\title{
Cognitive disorders associated with hip fracture surgery in the elderly. An observational study
}

Crespo-Santiago A. ${ }^{1}$, Varela N. ${ }^{1}$, Golvano-Sarriá M. ${ }^{1}$, Armendáriz-Buil I. ${ }^{1}$, Pérez-Pevida B. ${ }^{2}$

${ }^{1}$ Hospital San Pedro, Departamento de Anestesiología y Reanimación, Logroño, Spain

${ }^{2}$ Clinica Universidad de Navarra, Departamento de Endocrinología y Nutrición, Pamplona, Spain

\section{Background:}

Hip fracture is a common condition in older people, and most of them require surgical repair. $40 \%$ of the fractured patients present cognitive disorder. Current literature reflects the need for an interdisciplinary approach in these patients to prevent cognitive impairment and provide fast recovery to reduce the risk of loss of autonomy in the long-term approach.

Thus, the present study examines the rate of cognitive disorders associated with surgery for hip fracture.

\section{Materials and methods:}

We conducted an observational descriptive pilot study in which patients aged 65 years or above, who had a hip fracture and where scheduled for surgical repair of hip were recruited.

A Mini-Mental cognitive test (MMSE. Minimental- State Examination of Folstein) was performed. We avoided to perform the MMSE in the morning of the surgery to avoid bias (anxiety medication administered the night before or prior to surgery).

Epidemiologic, analytical and pain data were also collected (age, sex, date of admission, hematocrit, VAS) as well as anaesthetic/surgical and PACU data.

A second MMSE was was done when patient was discharged from the PACU to the ward and a third one $24 \mathrm{~h}$ after surgery.

\begin{tabular}{|c|c|c|}
\hline \multirow{2}{*}{$\begin{array}{l}\text { Sex } \\
\text { n (\%) }\end{array}$} & Male & $3(18 \%)$ \\
\hline & Female & 14 (82\%) \\
\hline \multirow{2}{*}{$\begin{array}{l}\text { Anaesthetic } \\
\text { technique } \\
\text { n (\%) }\end{array}$} & $\begin{array}{l}\text { General } \\
\text { Anaesthesia }\end{array}$ & I (6\%) \\
\hline & $\begin{array}{l}\text { Regional } \\
\text { Anaesthesia }\end{array}$ & $16(94 \%)$ \\
\hline \multirow{3}{*}{$\begin{array}{l}\text { Surgical technique } \\
\text { n (\%) }\end{array}$} & Gamma Nail & 10 (59\%) \\
\hline & $\begin{array}{l}\text { Partial Hip } \\
\text { Replacememt }\end{array}$ & $4(23 \%)$ \\
\hline & $\begin{array}{l}\text { Total Hip } \\
\text { Replacement }\end{array}$ & 3 (I8\%) \\
\hline
\end{tabular}

\section{Results:}

Seventeen cases were recorded with average age 83.I years old. Sixteen patients underwent regional anaesthesia whereas I surgery was done under general anaesthesia.

Before surgery, $33 \%$ of those aged $<80$ presented mild cognitive disorders, $50 \%$ of those aged $>80$.

After surgery, only I patient did not present changes in the mini-mental test, 8 presented mild changes, 5 moderate changes and 3 patients presented severe changes. None of all presented delirium.

We also found an association of impairment with transfusion needs, use of vasopressors and sedation.

\section{Discussion:}

Although our pilot study lacks of a great number of patients, the primary results obtained shows that cognitive deterioration is very important in older patients scheduled for hip repair surgery.

A great difference between Spain and other countries is the number of hip repairs realised under regional anaesthesia (90\%). A greater multicentric study with other countries would be interesting in order to compare both techniques.

\section{Conclusion:}

MINI-MENTAL CHANGES

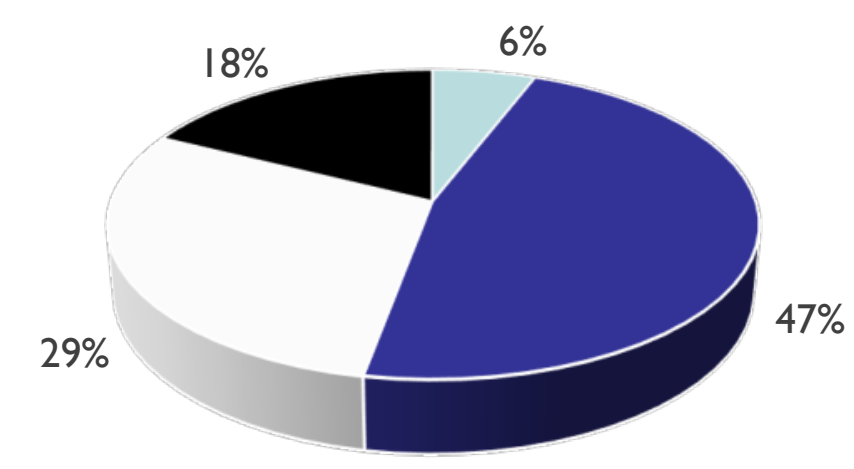

Hip repair in the elderly is associated with an important rate of cognitive impairment.

Larger studies are needed in order to confirm these results. 